\title{
EDITORIAL
}

\section{DE LA RABIA HUMANA DE ORIGEN CANINO Y OTRAS VERGÜENZAS}

\author{
FROM THE HUMAN RABIE OF CANINE ORIGEN AND OTHER \\ SHAMES
}

Colombia invierte cerca de diez puntos de su PIB en salud, sin embargo, sus indicadores de salud pública desdicen de la efectividad de su sistema sanitario. A las ya altas tasas de prevalencia e incidencia de patologías controlables o erradicables, como malaria, dengue clásico y hemorrágico, fiebre amarilla, tuberculosis, cólera y leishmaniasis, se agrega otra vergüenza: los brotes de rabia humana de origen canino recientemente observados en la región caribe colombiana.

La rabia es una enfermedad letal transmitida al hombre por animales do mésticos o silvestres producida por el virus rábico perteneciente al género Lyssavirus de la familia Rhabdoviridae, prevenible mediante vacunación. Los mecanismos para evitar muertes por rabia están desarrollados y bien descritos: a) cortar la cadena de transmisión del virus en especies domésticas (vacunación, manejo de poblaciones de perros y atención de focos); b) aplicación oportuna de tratamientos pre y post exposición a personas en riesgo; c) Vigilancia epidemiológica y monitoreo y control de la enfermedad en especies silvestres.

En el informe final sobre "Evaluación del Programa Nacional de rabia de Colombia", realizado por la organización Panamericana de la Salud y el Ministerio de la Protección Social en 2003 se destaca: "... la rabia transmitida por el perro aún constituye una situación preocupante en Colombia, además de los pocos casos registrados en los últimos años. Persisten situaciones de circulación viral, fundamentalmente en los departamentos de la costa atlántica que requieren de la aplicación de medidas de emergencia.." (1). Sin embargo, al parecer tales medidas quedaron solo en simples recomendaciones de política sin que las mismas hubiesen sido tenidas en cuenta, con los resultados ya conocidos y sin que aparecieran los responsables. En el citado informe se revela que entre los años 1995 a 2003 la región de la región caribe colombiana presentó el mayor número de defunciones por rabia humana del período (17 casos); seguida de la región occidental (5 casos), la 0 rinoquia (3 casos), la Amazonía (2 casos) y la Región Central, un sólo caso en el 2003 . Es decir todo estaba anunciado.

Los muertos se presentaron como consecuencia de la mordedura de perros infectados con el virus de la enfermedad, en diciembre de 2006 . El Instituto Nacional de Salud confirmó los casos y estimó éste como el brote mas grave, luego del ocurrido entre mayo y julio del 2004 en el que se notificaron 14 casos en el Bajo Baudó, por mordedura de murciélago. Cabe aclarar que se trata de un tipo de virus distinto al transmitido por caninos.

Según informes de la Secretaría de Salud de Santa Marta, al parecer las víctimas fueron mordidas en septiembre. La primera falleció el 5 de noviembre, la segunda 20 días después y la tercera el 16 de enero. Uno de los indicadores a partir de los cuales deben generarse alertas es la presencia de rabia animal. Ya para el 2005, el departamento del Magdalena mostraba el mayor número de casos reportados en el país: 18 de los 97 registrados. 
En el informe se destaca a pie de pagina: "El grupo evaluador, en virtud de razones epidemiológicas, operativas y políticas considera necesario resaltar la urgencia de esta recomendación considerando que la situación de rabia transmitida por el perro en los Departamentos de la Costa es un asunto que requerirá la intervención directa de las mas altas autoridades nacionales para evitar casos humanos prevenibles que se ven como altamente probables en un futuro próximo de persistir la situación actual. El virus de la rabia necesita de la existencia de perros no vacunados para sostenerse en la población canina e inesperadamente afectar a una persona si no se la trata oportunamente. El deficiente esquema de vacunación que se verificó en los departamentos de la costa, sumado a situaciones ecológicas particulares y a deficiencias en el control de focos, permite al virus circular y manifestarse - de cuando en cuando - en casos caninos y humanos". Las recomendaciones son elocuentes, sin embargo, las acciones fueron negligentes y el costo fueron muertes evitables, sin que aparezcan los responsables.

Por otro lado, la preocupación respecto a esta zoonosis no debe incluir solo la vigilancia de la población canina. Dadas las características ecológicas y sociales de las áreas tropicales y subtropicales de las Américas, la rabia transmitida por murciélagos hematófagos (vampiros generalmente de la especie Desmodus rotundus) adquiere una particular gravedad para la salud pública. En ecosistemas de alta densidad ganadera los vampiros se alimentan exclusivamente de ganado y atacan a las personas sólo esporádicamente. Por el contrario en los sistemas de baja densidad ganadera las poblaciones de vampiros son más pequeñas, se alimentan de varias especies animales y atacan a los humanos más frecuentemente. En general, se ha encontrado que la frecuencia de agresiones de los vampiros al hombre se ve influenciada por ciertas intervenciones, las más comunes son el retiro de animales de una zona densamente poblada; el inicio de las actividades de desmonte; y la exploración de minas $(2,3)$.

Colombia, que dispone hoy de casi tres veces más recursos para salud que hace 15 años, debería contar con un sistema sanitario con mayor centralidad en la Salud Publica. Se espera que en la próxima reforma al sistema de salud que se encuentra en trámite actualmente en el Congreso de la República (Plan Nacional de Salud Pública) el cual se expresará en el respectivo Plan Nacional de Desarrollo, pueda revisar y corregir estas vergüenzas.

Nelson Alvis G, Ph.D.

Editor invitado

\section{REFERENCIAS}

1. O PS. Ministerio de la Protección Social. EVALUACIÓ N DEL PRO G RAMA NACIO NAL DE RABIA DE CO LO MBIA. Disponible en internet en: http://www.paho.org/cdmedia/hdmvpol/docs.rabia/paises/ EVAL.RABIA.CO LO MBIA.pdf. consultado el 27 de diciembre de 2006

2. Schneider MC, Aron J, Santos-Burgoa C, Uieda W, Ruiz Velazco S. Common vampire bat attacks on humans in a village of the Amazon region of Brazil. Cad Saude Publica 2001;17:1531-1536.

3. Schneider MC, Santos-Burgoa C, Aron J, Munoz B, Ruiz-Velazco S, Uieda W. Potential force of infection of human rabies transmitted by vampire bats in the Amazonian region of Brazil. Am J Trop Med Hyg 1996;55:680-684 